\title{
Synthesis of multi-walled and single-walled nanotubes, aligned-nanotube bundles and nanorods by employing organometallic precursors
}

\author{
Received: 31 July 1998 / Accepted: 28 August 1998
}

\begin{abstract}
Pyrolysis of organometallic precursors such as metallocenes and iron pentacarbonyl as well as of their mixtures with hydrocarbons such as acetylene or benzene has been carried out under a variety of conditions to synthesize nanotubes. While the use of benzene as a hydrocarbon source generally yields multi-walled nanotubes, it has been possible to obtain single-walled nanotubes $(\sim 1 \mathrm{~nm}$ diameter $)$ by pyrolyzing a metallocene or a mixture of metallocenes along with acetylene under a high flow rate of Ar. These experiments show that the organometallic precursor produces small nanoparticles of $\sim 1 \mathrm{~nm}$ diameter which then catalyze the formation of the single-walled nanotubes. Copious quantities of alignednanotube bundles have been obtained by the pyrolysis of acetylene in the presence of high concentrations of ferrocene. Nanorods have been produced by the pyrolysis of ferrocene under vacuum. Single walled nanotubes can be filled or decorated by metals.
\end{abstract}

Key words Carbon nanotubes $\cdot$ Single-walled nanotubes $\cdot$ Aligned nanotube bundles $\cdot$ Nanorods

\section{Introduction}

Since the discovery of carbon nanotubes, there has been considerable effort to prepare them by different methods. Traditionally, carbon nanotubes have been prepared by arc-evaporation of graphite electrodes [1]. The nanotubes collected at the cathode are generally multi-walled, comprising several graphite layers around the central tubule. Multi-walled nanotubes (MWNTs) can also be prepared by the decomposition of hydrocarbons such as acetylene

C.N.R. Rao (- A. Govindaraj · Rahul Sen · B.C. Satishkumar CSIR Centre of Excellence in Chemistry and Solid State and Structural Chemistry Unit, Indian Institute of Science, Bangalore 560 012, India and

Jawaharlal Nehru Centre for Advanced Scientific Research, Bangalore 560 064, India

e-mail: cnrrao@sscu.iisc.ernet.in or benzene over small metal particles [2-5]. The metal particles are found to be essential for the formation of nanotubes by the decomposition of hydrocarbons. The size of the metal particles plays a crucial role in determining the nature of the nanotubes obtained. Thus, very small metal nanoparticles $(\leq 5 \mathrm{~nm})$ can yield singlewalled nanotubes (SWNTs) [6]. Large metal particles do not yield nanotubes, but instead give rise to metal carbides or metal particles covered by graphene sheets. Since the metal particles play such a crucial role in the formation of nanotubes by the pyrolysis of hydrocarbons, it was our view that there may be considerable advantage in making use of organometallic precursor molecules which on decomposition not only act as a source of carbon but also give rise to small metal clusters or particles which act as catalysts to form the nanotubes. We have therefore made use of organometallic precursors such as metallocenes and iron pentacarbonyl to explore this idea [7]. Furthermore, we have investigated whether SWNTs can be prepared by a careful control of the preparative conditions as well as the relative proportions of the organometallic precursor and the hydrocarbon source. SWNTs are usually prepared by metal catalyzed arc evaporation of graphite electrodes [8] or laser vaporization of transition metal containing graphite targets $[9$, 10].

An aspect of interest to us investigate whether by the decomposition of organometallic precursors along with hydrocarbons, one could obtain aligned nanotube bundles. Aligned nanotube bundles have hitherto been obtained by very complex procedures. One of the procedures employed is to pass a dispersion of arc-produced carbon nanotubes in ethanol through an alumina micropore filter and then press the nanotube-covered filter onto a polymer sheet [11]. Under pressure, the nanotubes are printed onto the polymer sheet in an aligned manner. Aligned nanotubes have also been obtained by the chemical vapour deposition of acetylene catalyzed by iron nanoparticles embedded in mesoporous silica [12], the pores of the silica controlling the growth direction of the nanotubes. Aligned-nanotube bundles have been prepared 
Fig. 1a-c Pyrolysis apparatus employed for the synthesis of carbon nanotubes by pyrolysis of mixtures of (a) metallocene + benzene (b) metallocene + acetylene and $(\mathbf{c}) \mathrm{Fe}(\mathrm{CO})_{5}$ + acetylene
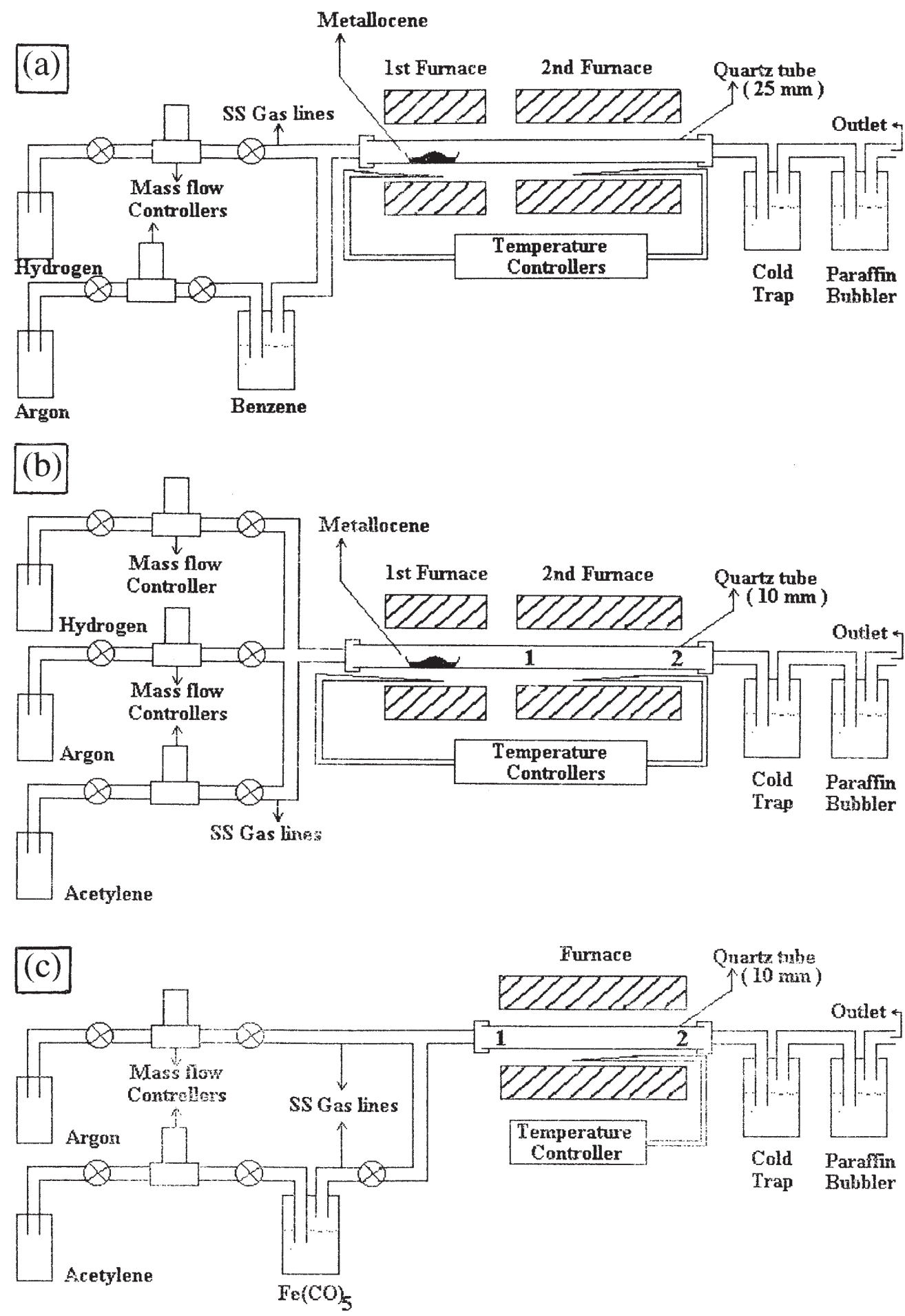

recently by the pyrolysis of 2-amino-4,6-dichloro-s-triazine over thin films of a cobalt catalyst, patterned on a silica substrate by laser etching [13]. A salient feature of the precursor strategy employed by us is the ease of control of the relative concentrations or partial pressures of the organometallic precursor and hydrocarbon in the vapour phase, achieved by manipulating the flow rates of the different gaseous species through mass flow controllers. By this means, we expected to prepare SWNTs at one end and aligned nanotube bundles at the other. In this article we report the successful results we have obtained with this relatively simple chemical strategy.

\section{Experimental}

In order to prepare MWNTs by metallocene pyrolysis, the set-up shown in Fig. 1(a) was employed. The pyrolysis set-up consists of stainless steel gas flow lines and a two-stage furnace system fitted 

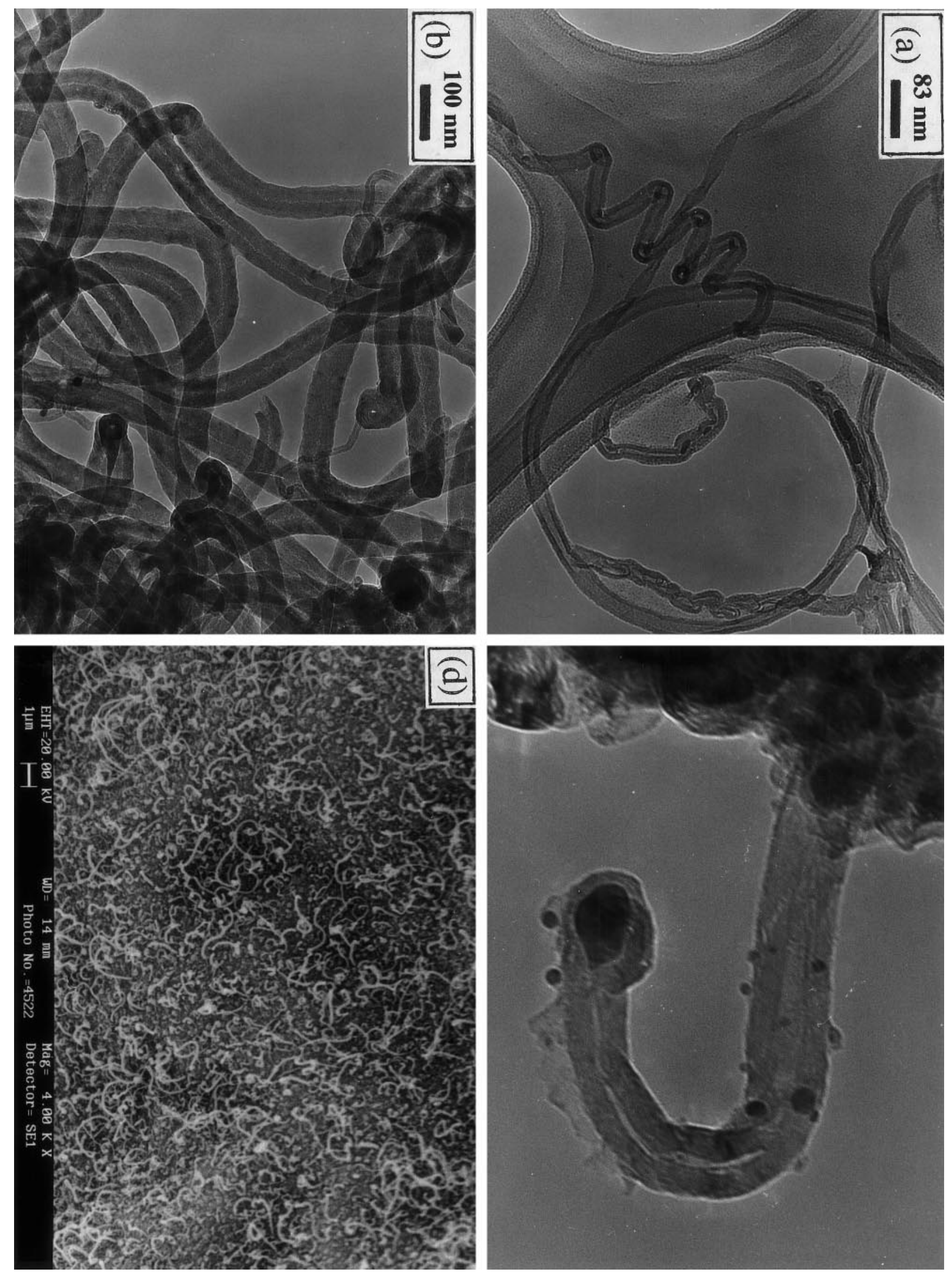

Fig. 2a-d TEM images of carbon nanotubes obtained by the pyrolysis of a mixture of ferrocene and benzene (a), a mixture of nickelocene and benzene at $1173 \mathrm{~K}$ in $85 \% \mathrm{Ar} 15 \% \mathrm{H}_{2}$ mixture at a flow rate of $1000 \mathrm{sccm}$ (b) and a mixture of cobaltocene and

benzene at $1173 \mathrm{~K}$ in a stream of $75 \% \mathrm{Ar}$ and $25 \% \mathrm{H}_{2}$ at a flow rate of $50 \mathrm{sccm}$ (c). SEM image of carbon nanotubes obtained by the pyrolysis of a mixtures of cobaltocene and acetylene $(50 \mathrm{sccm})$ at $1373 \mathrm{~K}$, in $\mathrm{Ar}+\mathrm{H}_{2}$ flow (total flow rate $\left.=1000 \mathrm{sccm}\right)(\mathbf{d})$ 

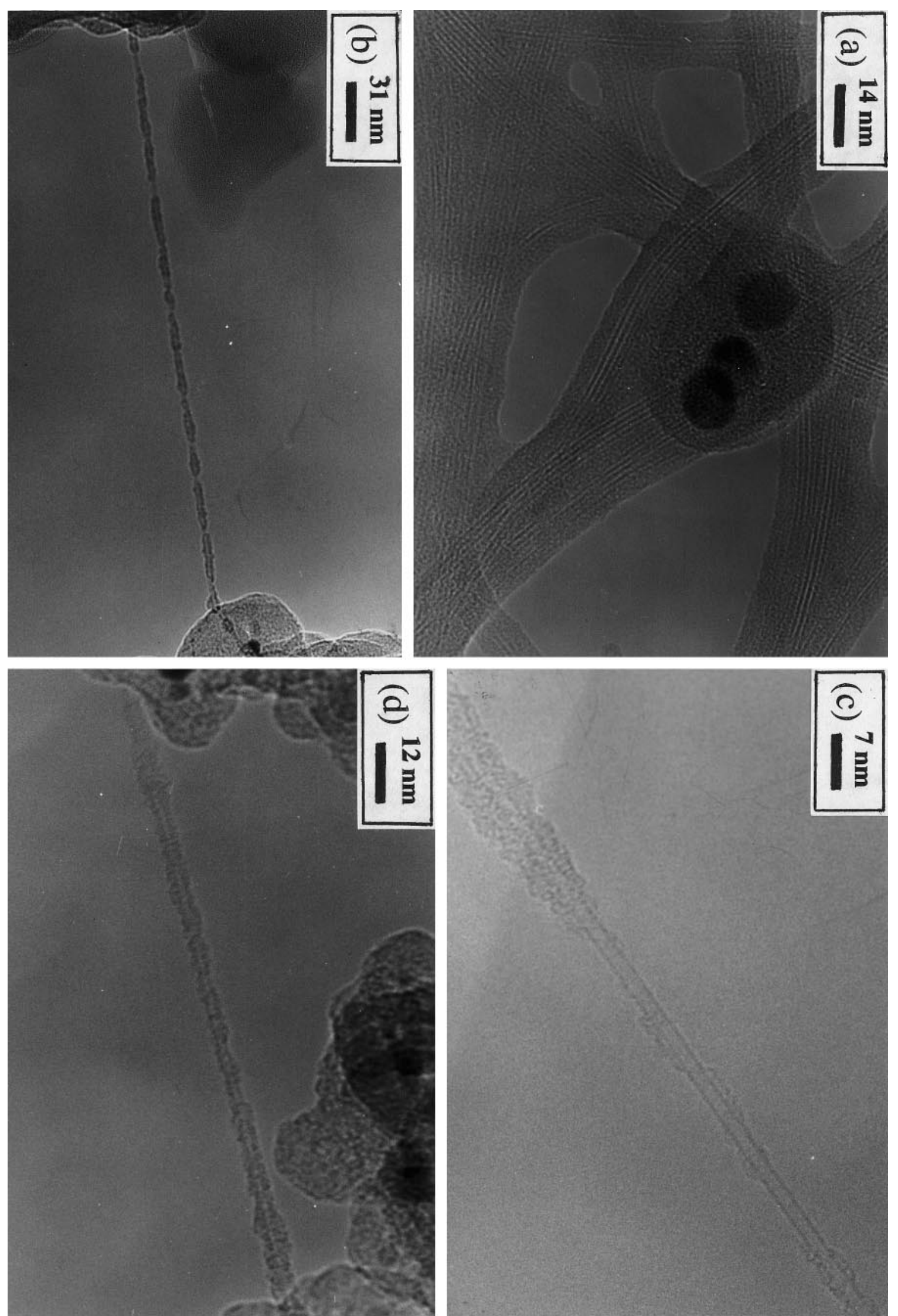

Fig. 3a-d HREM images of SWNTs obtained by arcing graphite rods filled with $\mathrm{Ni}$ and $\mathrm{Y}_{2} \mathrm{O}_{3}$ in $\mathrm{He}$ (660 Torr) (a), and SWNTs obtained by the pyrolysis of a mixture of nickelocene and acetylene

(50 sccm) at $1373 \mathrm{~K}$ in Ar flow (1000 sccm) (b) (c) and a SWNT obtained by the pyrolysis of a mixture of nickelocene and acetylene $(25 \mathrm{sccm})$ at $1373 \mathrm{~K}$ in $\mathrm{Ar}(975 \mathrm{sccm})$ and $\mathrm{H}_{2}(25 \mathrm{sccm})$ flow $(\mathbf{d})$ 
with a quartz tube $(25 \mathrm{~mm}$ inner diameter, i.d.). The flow rate of the gases was controlled using UNIT mass flow controllers. A known quantity $(\sim 100 \mathrm{mg}$ ) of the metallocene (of $99 \%$ purity) was taken in a quartz boat and placed inside the first furnace. The metallocene was sublimed by raising the temperature of this furnace to $623 \mathrm{~K}$ at a controlled heating rate. Argon gas, bubbled at a desired flow rate through a known quantity of benzene $(\sim 5 \mathrm{ml})$ was mixed with hydrogen gas and passed through the quartz tube. The $\mathrm{Ar} / \mathrm{H}_{2}$ gas ratio was maintained at $75 \% / 25 \%$ or $85 \% / 15 \%$ and the total gas flow rate was kept at $50 \mathrm{sccm}$ or $1000 \mathrm{sccm}$ ( $\mathrm{sccm}=\mathrm{stan}-$ dard cubic centimeter per minute). The metallocene vapour was carried by this gas mixture into the second furnace maintained at $1173 \mathrm{~K}$. The pyrolysis yielded copious quantities of carbon deposits inside the second furnace.

In order to prepare SWNTs by metallocene pyrolysis, the setup shown in Fig. 1(b) was employed. The pyrolysis set-up consists of a two-stage furnace system fitted with a quartz tube $(10 \mathrm{~mm}$ i.d). The metallocene placed in the first furnace was sublimed by raising the temperature of this furnace to $623 \mathrm{~K}$ at a heating rate of $100 \mathrm{deg} \mathrm{min}^{-1}$ Argon and acetylene were passed through the quartz tube at flow rates of $1000 \mathrm{sccm}$ and $50 \mathrm{sccm}$ respectively. The metallocene vapour was carried by this gas mixture into the second furnace maintained at $1373 \mathrm{~K}$. The pyrolysis yielded copious quantities of carbon deposits inside the second furnace. SWNTs were mainly found at the outlet end of the second furnace marked 2 in Fig. 1(b), while MWNTs were present at the inlet end, marked 1.

$\mathrm{Fe}(\mathrm{CO})_{5}$ was pyrolyzed along with acetylene by using the setup shown in Fig. 1(c). Acetylene (flow rate $=50 \mathrm{sccm}$ ) was bubbled through a known quantity of $\mathrm{Fe}(\mathrm{CO})_{5}(1 \mathrm{ml})$ and the mixture carried by argon gas (flow rate $=1000 \mathrm{sccm}$ ) into the furnace, maintained at $1373 \mathrm{~K}$. The argon gas acts as a dilution agent. SWNTs were found at the outlet end of the furnace marked 2 in the Fig. 1(c), MWNTs being present at the inlet end, marked 1. For purpose of comparison, we also synthesized SWNTs by the arcevaporation of graphite electrodes filled with $\mathrm{Y}_{2} \mathrm{O}_{3}$ and $\mathrm{Ni}$ powder ( 1 at.\% Y and 4.2 at.\% Ni) in a He atmosphere of 660 Torr. The graphite rods $(6 \mathrm{~cm}$ long, $6 \mathrm{~mm}$ dia. with a $4 \mathrm{~mm}$ dia. hole drilled in the centre) filled with $\mathrm{Y}_{2} \mathrm{O}_{3}, \mathrm{Ni}$ and graphite powder were treated with hydrogen at $973 \mathrm{~K}$ for $3 \mathrm{~h}$, prior to arcing.

For the preparation of aligned nanotube bundles, pyrolysis of ferrocene was carried out as follows. A known quantity (100 mg) of ferrocene (presublimed $99.99 \%$ purity) was taken in a quartz boat located at one end of a narrow quartz tube $(10 \mathrm{~mm}$ i.d.), which in turn was placed in a dual furnace system (see Fig. 1(b)). The part of the quartz tube containing the ferrocene was in the first furnace and the ferrocene was sublimed by raising the temperature of this furnace to $623 \mathrm{~K}$ at a controlled heating rate. Argon gas was passed through the quartz tube at a desired flow rate. The ferrocene vapour was carried by the Ar gas into the second furnace, maintained at $1373 \mathrm{~K}$, where pyrolysis occurred. The main variables in the experiments were the heating rate of ferrocene, flow rate of the argon gas and pyrolysis temperature. Large quantities of deposits accumulated at the inlet of the second furnace.

The carbon products were sonicated in carbon tetrachloride and loaded onto holey carbon copper grids. Transmission electron microscopy (TEM) was performed with a JEOL JEM-3010 microscope operating at $300 \mathrm{kV}$. The microscope is equipped with a Gatan fiber optically coupled TV system, model 622SC for high resolution imaging. Scanning electron microscopy (SEM) was performed on the as-prepared samples using a LEICA S440i instrument.

\section{Results and discussion}

Our first experiments were directed towards establishing the viability of the synthetic strategy, by carrying out the pyrolysis of hydrocarbons such as benzene in mixture with metallocene. We indeed found that in the presence
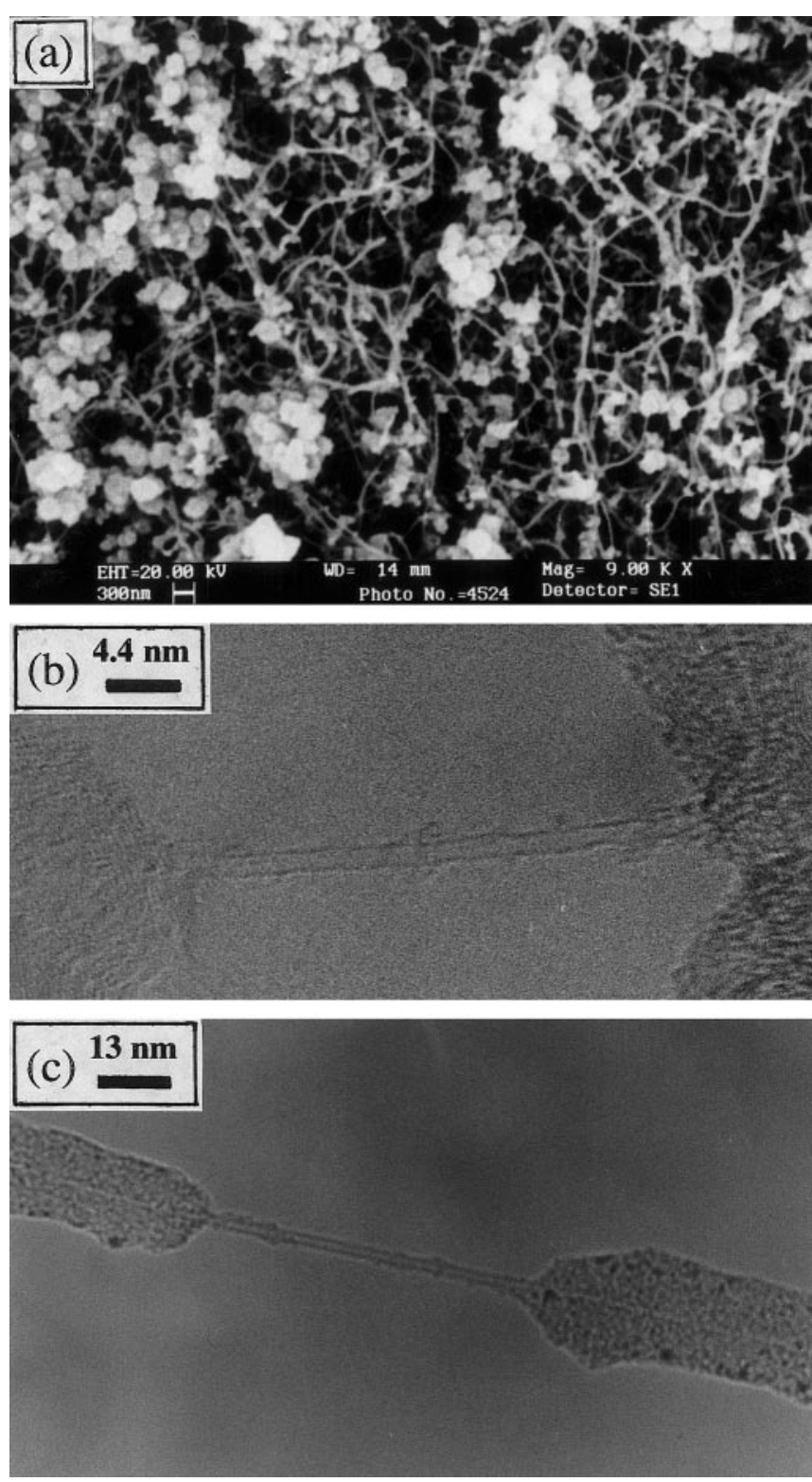

Fig. 4a-c SEM image of SWNTs obtained by the pyrolysis of a mixture of cobaltocene and acetylene $(50 \mathrm{sccm})$ at $1373 \mathrm{~K}$ in $\mathrm{Ar}$ $(975 \mathrm{sccm})$ and $\mathrm{H}_{2}(25 \mathrm{sccm})$ flow (a). HREM images of the SWNTs (b and $\mathbf{c}$ ). The image in (c) shows extensive coating of amorphous carbon on the nanotube

of a small proportion of metallocene, pyrolysis of benzene, employing the apparatus in Fig. 1(a), yields large quantities of carbon nanotubes. In Fig. 2(a) we show the TEM image of nanotubes obtained by the pyrolysis of benzene in the presence of ferrocene at $1273 \mathrm{~K}$ in $85 \%$ $\mathrm{Ar}-15 \% \mathrm{H}_{2}$ at a total gas flow rate of $1000 \mathrm{sccm}$. Pyrolysis of benzene and nickelocene under similar conditions also yields large quantities of nanotubes, as seen in Fig. 2(b). In Fig. 2(c) we show the TEM image of a thick nanotube obtained by the pyrolysis of benzene along with cobaltocene at $1273 \mathrm{~K}$ in a stream of $75 \% \mathrm{Ar}$ and $25 \% \mathrm{H}_{2}$ (total gas flow rate=50 sccm). The metal particle can be clearly seen at the tip of this nanotube indicating 

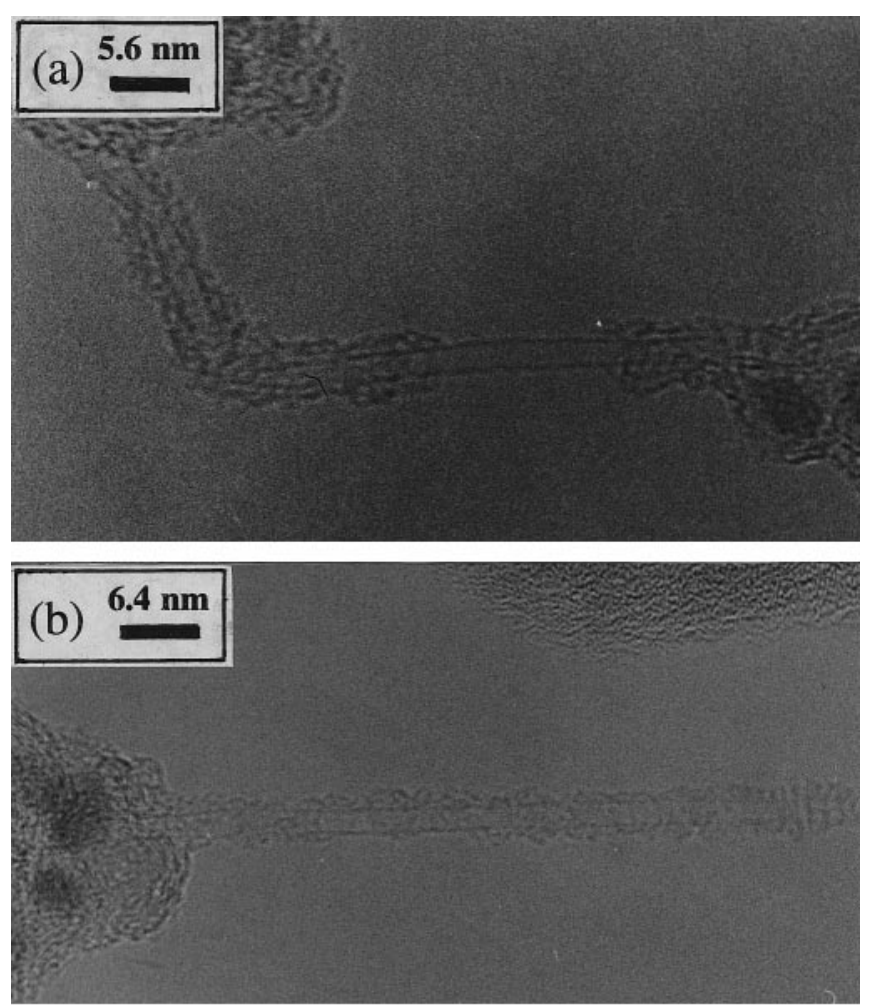

\section{(c) $8 \mathrm{~nm}$}

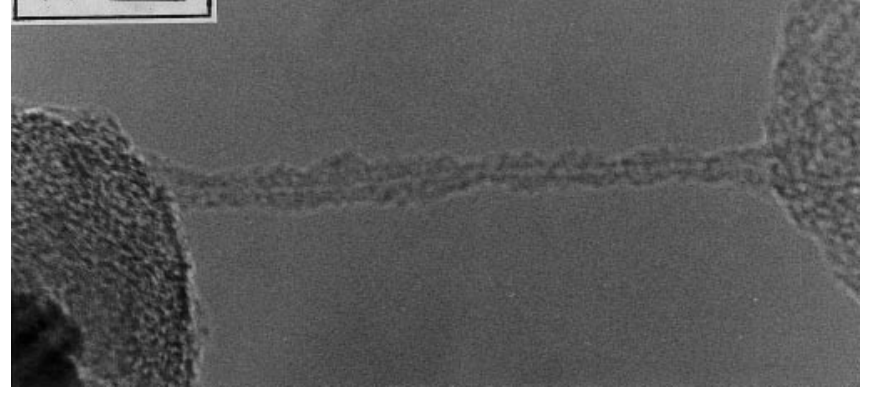

Fig. 5a-c HREM images of SWNTs obtained by the pyrolysis of a mixture of acetylene $(50 \mathrm{sccm})$ with cobaltocene + ferrocene (1:1) (a), nickelocene + cobaltocene (1:1) (b) and ferrocene + nickelocene $(1: 1)$ at $1373 \mathrm{~K}$ in $\mathrm{Ar}(975 \mathrm{sccm})$ and $\mathrm{H}_{2}(25 \mathrm{sccm})$ flow (c)

that the metal particle catalyses the nanotube formation. The microscopic images in Fig. 2 clearly show that the nanotubes are multi-walled. The wall thickness can however be controlled by adjusting the relative concentration of the metallocene and benzene in the vapour phase. In Fig. 2(d) we show a SEM image of carbon nanotubes obtained by the pyrolysis of cobaltocene and acetylene $(50 \mathrm{sccm})$ at $1373 \mathrm{~K}$, in $\mathrm{Ar}(975 \mathrm{sccm})$ and $\mathrm{H}_{2}(25 \mathrm{sccm})$ flow, by employing the apparatus in Fig. 1(b). These nanotubes are also multi-walled. These initial experiments on the pyrolysis of a mixture of benzene or acetylene with a metallocene established that MWNTs can readily be prepared by this method.

Having successfully obtained MWNTs by the pyrolysis of a mixture of a metallocene and hydrocarbon, we
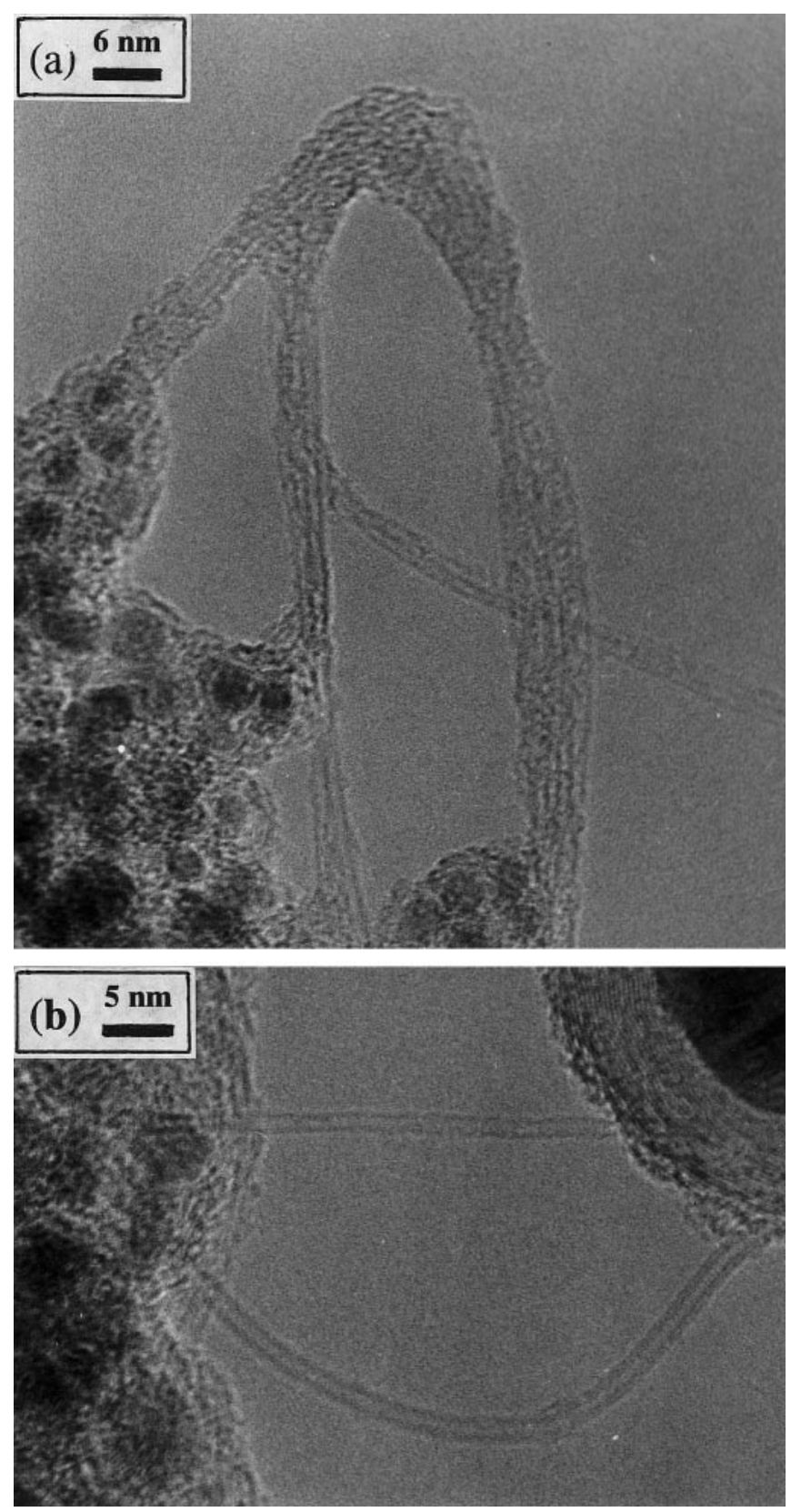

Fig. 6a, b HREM images of SWNTs obtained by the pyrolysis of a mixture of $\mathrm{Fe}(\mathrm{CO})_{5}$ and $\mathrm{C}_{2} \mathrm{H}_{2}(50 \mathrm{sccm})$ at $1373 \mathrm{~K}$ in $\mathrm{Ar}$ $(1000 \mathrm{sccm})$ flow (a), (b)

thought it should be possible to control the relative proportions of the metallocene and the hydrocarbon (which acts as an additional carbon source), to obtain SWNTs. We expected the formation of SWNTs at low concentration of carbon in the vapour phase. For purpose of comparision, we first prepared SWNTs by the arc-evaporation of graphite rods filled with $\mathrm{Ni}$ and $\mathrm{Y}_{2} \mathrm{O}_{3}$ in a He atmosphere (660 Torr). This procedure was similar to the one reported by Journet et al. [14], except that we have used $\mathrm{Y}_{2} \mathrm{O}_{3}$ instead of yttrium metal. The web-like deposit on the chamber walls near the cathode consists of SWNT bundles. The high resolution transmission elec- 
Table 1 Nature of the carbon nanotubes obtained by the pyrolysis of acetylene along with different organometallic precursors

Table 2 Nature of nanotubes and other products obtained by the pyrolysis of mixtures of organometallic precursors with hydrocarbons

(a) with benzene, only MWNTs
are obtained when the quartz
pyrolysis tube was of 25 mm
diameter. Experiments were not
carried out with the narrower
quartz tube employed with
acetylene

\begin{tabular}{|c|c|c|c|}
\hline \multirow[t]{2}{*}{ Organometallic precursor } & \multirow[t]{2}{*}{ Hydrocarbon source } & \multicolumn{2}{|c|}{ Nature of carbon nanotubes } \\
\hline & & Inlet & Outlet \\
\hline Ferrocene & Acetylene & Alligned MWNTs & $\begin{array}{l}\text { Metal encapsulated } \\
\text { graphite nanoparticles }\end{array}$ \\
\hline Nickelocene & Acetylene & MWNTs & SWNTs \\
\hline Cobaltocene & Acetylene & MWNTs & SWNTs \\
\hline Ferrocene + Nickelocene & Acetylene & Aligned MWNTs & SWNTs \\
\hline Ferrocene + Cobaltocene & Acetylene & Aligned MWNTs & SWNTs \\
\hline Nickelocene + Cobaltocene & Acetylene & MWNTs & SWNTs \\
\hline $\mathrm{Fe}(\mathrm{CO})_{5}$ & Acetylene & MWNTs & SWNTs (bundles) \\
\hline
\end{tabular}

\begin{tabular}{|c|c|c|}
\hline Precursor & Hydrocarbon source & Nature of carbon nanotubes and other products \\
\hline \multirow[t]{2}{*}{ Ferrocene $\mathrm{a}^{(\mathrm{a})}$} & nil & Mostly metal-filled MWNTs \\
\hline & acetylene & $\begin{array}{l}\text { Inlet: aligned nanotube bundles (MWNTs) } \\
\text { Outlet: metal encapsulated graphite nanoparticles }\end{array}$ \\
\hline \multirow[t]{2}{*}{ Nickelocene $^{(a)}$} & nil & $\begin{array}{l}\text { Inlet: metal-filled MWNTs } \\
\text { Outlet: metal encapsulated graphite nanoparticles }\end{array}$ \\
\hline & acetylene & $\begin{array}{l}\text { Inlet: MWNTs } \\
\text { Outlet: SWNTs }\end{array}$ \\
\hline \multirow[t]{2}{*}{ Coblatocene $^{(a)}$} & nil & $\begin{array}{l}\text { Inlet: metal-filled MWNTs } \\
\text { Outlet: metal encapsulated graphite nanoparticles }\end{array}$ \\
\hline & acetylene & $\begin{array}{l}\text { Inlet: MWNTs } \\
\text { Outlet: SWNTs }\end{array}$ \\
\hline \multirow[t]{5}{*}{$\mathrm{Fe}(\mathrm{CO})_{5}$} & nil & metal encapsulated graphite nanoparticles \\
\hline & $\begin{array}{l}\text { carbon } \\
\text { monoxide }\end{array}$ & $\begin{array}{l}\text { Inlet: uniformed sized }(1 \mathrm{~m}) \text { spherical particles } \\
\text { Outlet: nanosized spherical particles }\end{array}$ \\
\hline & methane & $\begin{array}{l}\text { Inlet: interconnected spherical particles } \\
\text { Outlet: spherical particles }\end{array}$ \\
\hline & acetylene & $\begin{array}{l}\text { Inlet: MWNTs } \\
\text { Outlet: SWNTs (bundles) }\end{array}$ \\
\hline & benzene & $\begin{array}{l}\text { Inlet: rod-like structures (metallic nanorods) } \\
\text { Outlet: non-uniformed sized particles }\end{array}$ \\
\hline
\end{tabular}

tron microscopic image (HREM) of SWNTs so prepared is shown in Fig. 3(a). The image shows bundles consisting of 10-20 SWNTs forming some kind of high-way junctions. The diameter of the SWNTs is in the range of 1-2 $\mathrm{nm}$ and the length extended up to several microns. Figure 3(b) and (c) show the TEM images of isolated SWNTs obtained by the pyrolysis of nickelocene and acetylene (flow rate $=50 \mathrm{sccm}$ ) at $1373 \mathrm{~K}$ in $\mathrm{Ar}$ (flow rate $=1000 \mathrm{sccm}$ ). The diameter of SWNT in Fig. 3(b) is $1.4 \mathrm{~nm}$. It is noteworthy that pyrolysis of nickelocene in admixture with benzene under similar conditions primarily yields MWNTs. Acetylene appears to be a better carbon source for the preparation of SWNTs, since it contains a smaller number of carbon atoms; it is possible that benzene favors the formation of MWNTs since it is more carbon-rich. The bottom portion of the SWNT in Fig. 3(b) shows an amorphous carbon coating around the tube. Indeed, a majority of the SWNTs show the presence of such amorphous carbon coating. This can be avoided by reducing the proportion of the hydrocarbon $\left(\mathrm{C}_{2} \mathrm{H}_{2}\right)$ and mixing hydrogen into the Ar stream. The
SWNTs obtained with Ar- $\mathrm{H}_{2}$ as the flow gas show less amorphous carbon deposition around the tubes, as revealed by the HREM image in Fig. 3(d). Pyrolysis of cobaltocene and acetylene under similar conditions also yields isolated SWNTs. The yield of SWNTs is considerably better with cobaltocene than with nickelocene. The SEM image in Fig. 4(a) demonstrates the high yield of SWNTs, present along with other carbonaceous deposits. In Fig. 4(b) and (c), we show the HREM images of SWNTs, with diameters of $1 \mathrm{~nm}$ and $1.5 \mathrm{~nm}$ respectively. Some of the nanotubes have an excessive coating of amorphous carbon as indicated by Fig. 4(c), where the coating is $\sim 7 \mathrm{~nm}$ thick.

Having succeeded in synthesizing SWNTs by the pyrolysis of metallocenes in admixture with acetylene, we carried out the pyrolysis of binary mixtures $(1: 1$ by weight) of metallocenes along with acetylene. This is because, binary metal alloys have been reported to give good yields of SWNTs by arc vaporization [15]. In Fig. 5(a) we show a HREM image of an isolated SWNT obtained on pyrolysis of acetylene (flow rate $=50 \mathrm{sccm}$ ) 

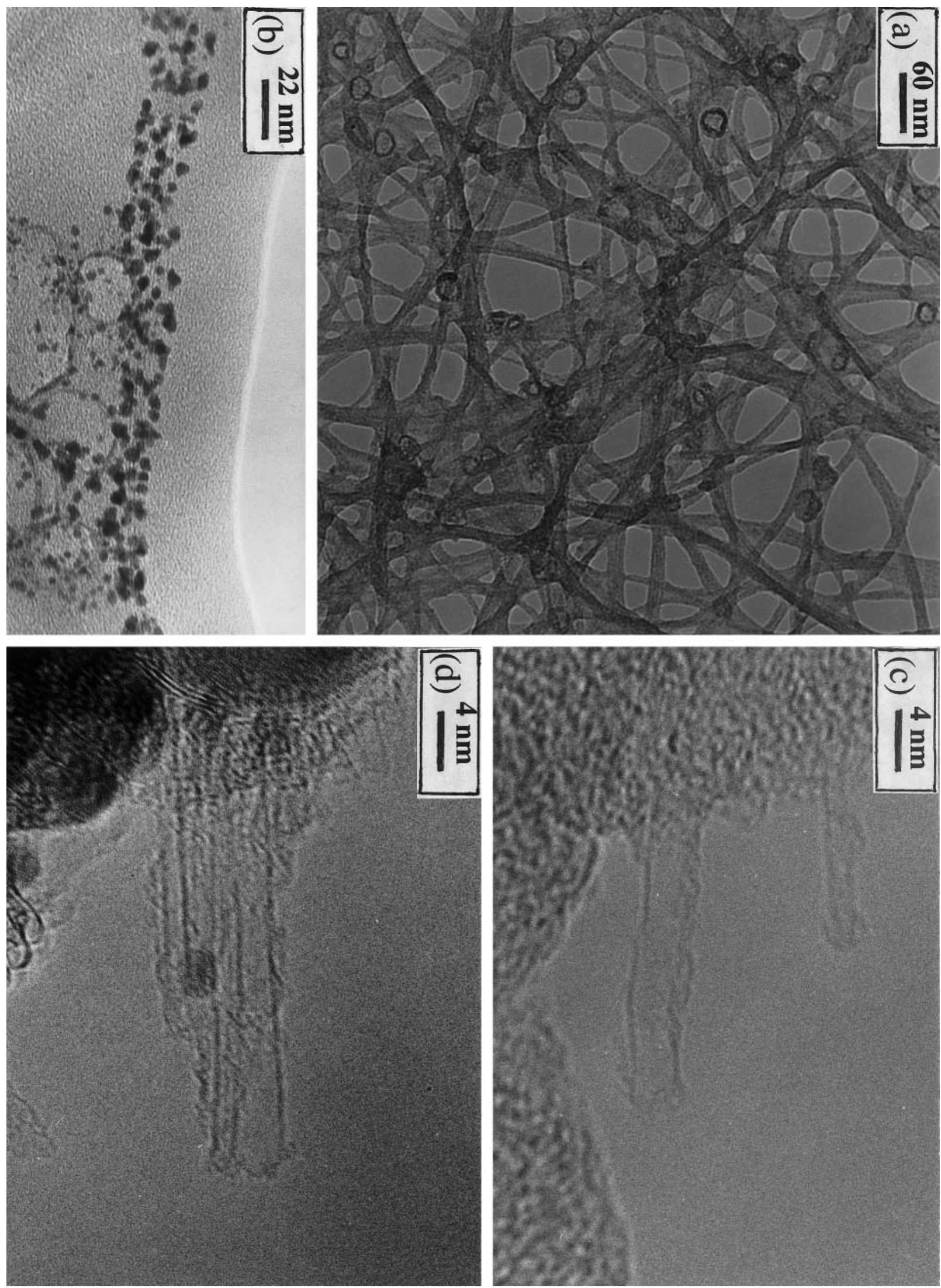

Fig. 7a-d HREM images of SWNTs cleaned by refluxing in nitric acid (a), a SWNT decorated by gold nanoparticles (b), SWNT opened by stirring with $\mathrm{HCl}$ for $5 \mathrm{~h}$ at room temperature (c) and a SWNT filled with a Pd particle (d) 

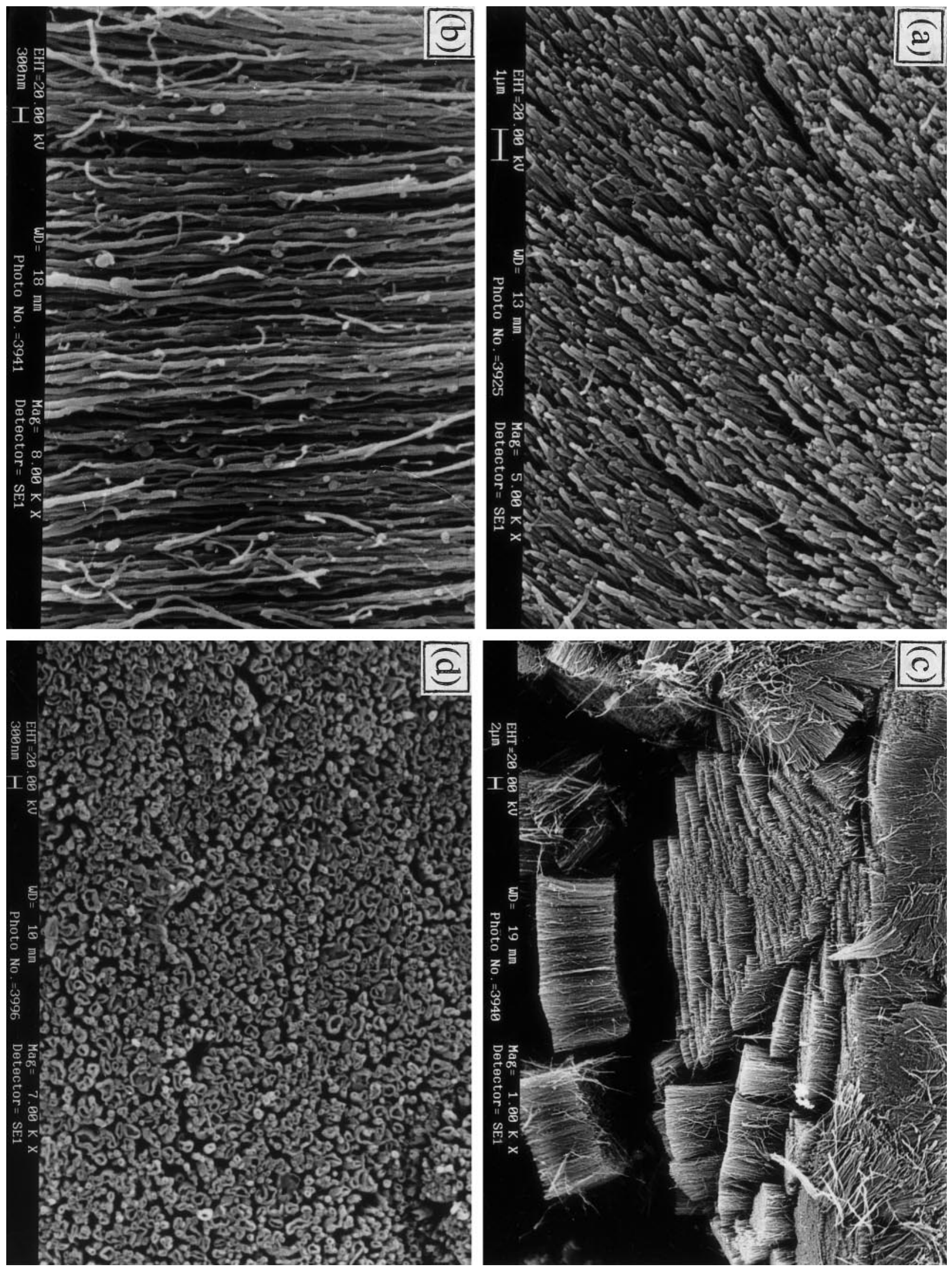

Fig. 8a-d SEM images of aligned-nanotube obtained by ferrocene pyrolysis. shows the view along the axis (a) and perpendicular to the axis of nanotubes (b). shows bundles of aligned-nanotube

(c). shows the top-view of aligned-nanotube bundles obtained by the pyrolysis of ferrocene under vacuum $\left(10^{-5}\right.$ Torr $)$ at a slow heating rate of 1 deg $\min ^{-1}(\mathbf{d})$ 

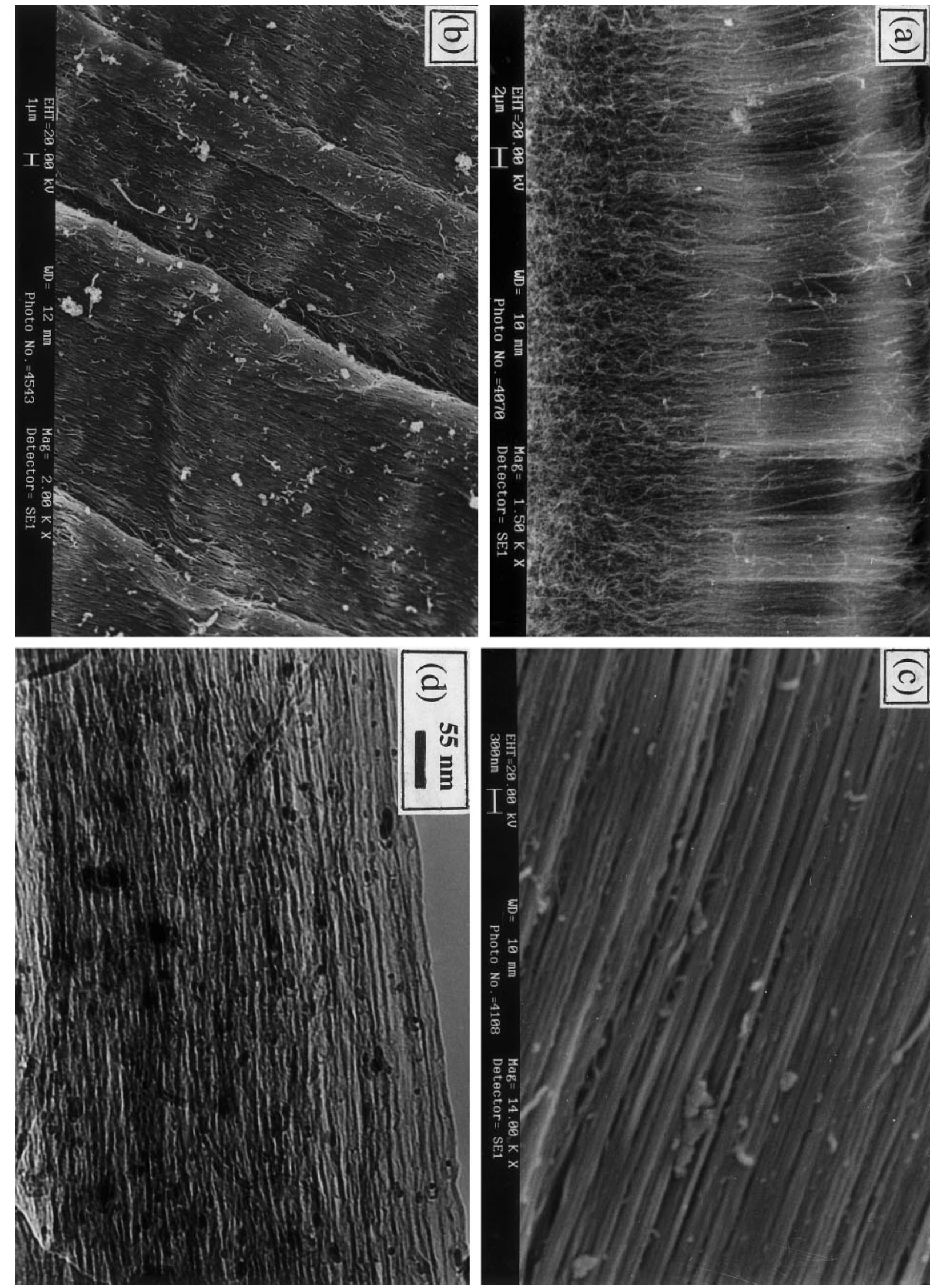

Fig. 9a-d SEM image of aligned-nanotube bundles obtained by the pyrolysis of ferrocene at $1373 \mathrm{~K}$ under a flow of $\mathrm{C}_{2} \mathrm{H}_{2}$ $(5 \mathrm{sccm})$ and $\operatorname{Ar}(1000 \mathrm{sccm})(\mathbf{a})$. shows the SEM image of aligned-nanotube bundles obtained under $\mathrm{C}_{2} \mathrm{H}_{2}$ flow of $50 \mathrm{sccm}$

(b). show respectively the SEM and TEM images of densely packed aligned nanotubes obtained with a higher proportion of $\mathrm{C}_{2} \mathrm{H}_{2}(85 \mathrm{sccm})$ in the reaction mixture (c and $\left.\mathbf{d}\right)$ 
with a cobaltocene-ferrocene mixture at $1373 \mathrm{~K}$ in a flow of $\mathrm{Ar}$ (flow rate=975 $\mathrm{sccm}$ ) and $\mathrm{H}_{2}$ (flow rate $=25 \mathrm{sccm}$ ). Figure 5(b) and (c) show the HREM images of a SWNT from the pyrolysis of acetylene with a nickelocene-cobaltocene mixture and a ferrocene-nickelocene mixture respectively, obtained under similar conditions. We have not found major differences in the yields of SWNTs by using binary mixtures of metallocenes instead of a single metallocene. However, the nanotubes are somewhat cleaner with the use of the mixture. Occasionally SWNT bundles are obtained when binary mixtures of metallocenes are used as metal precursors.

We have employed $\mathrm{Fe}(\mathrm{CO})_{5}$ as a source of the metal instead of metallocenes and carried out the pyrolysis of acetylene in mixture with the carbonyl at $1373 \mathrm{~K}$. Interestingly, SWNTs were obtained by this method as well. The flow rate of acetylene was maintained at $50 \mathrm{sccm}$ and the Ar flow rate at $1000 \mathrm{sccm}$. The TEM image in Fig. 6(a) shows the presence of a few SWNTs along with metal encapsulated graphite nanoparticles. The image in Fig. 6(b) show single-walled tubes with diameters in the $0.9-1.5 \mathrm{~nm}$ range. SWNT bundles are more frequently found when $\mathrm{Fe}(\mathrm{CO})_{5}$ is used as the organometallic precursor.

It appears from the above study that the type of the nanotubes produced depends somewhat on the nature of the organometallic precursor used. Table 1 summarizes the nature of the carbon nanotubes and other species obtained by the pyrolysis of acetylene along with different organometallic precursors. Precursors like nickelocene and cobaltocene favor the formation of SWNTs, while ferrocene favors the formation of aligned MWNTs. It is noteworthy that pyrolysis of mixture of ferrocene with nickelocene or cobaltocene along with acetylene yields aligned MWNTs at the inlet and SWNTs at the outlet. The nature of nanotubes and nanoparticles formed by the pyrolysis of a mixture of an organometallic and a hydrocarbon not only depends on the organometallic precursor but also on the hydrocarbon source. Table 2 summarizes the different types of nanostructures formed by the pyrolysis of organometallic precursors along with different hydrocarbon sources. Pyrolysis of ferrocene alone yields metal-filled MWNTs and an additional hydrocarbon source the yield of MWNTs is increased. The pyrolysis of nickelocene or cobaltocene also yields metal-filled MWNTs at the inlet and metal-encapsulated graphite nanoparticles at the outlet. The inclusion of acetylene however yields MWNTs at the inlet and SWNTs at the outlet. Further increase in the carbon content of the hydrocarbon source, by using benzene, gives high yields of MWNTs. Pyrolysis of $\mathrm{Fe}(\mathrm{CO})_{5}$ alone gives metal-encapsulated graphite nanoparticles. With an additional carbon source such as $\mathrm{CO}$ or $\mathrm{CH}_{4}$, which has less carbon, yields spherical carbon coated metal particles, but no nanotubes. Nanotubes are obtained by increasing the carbon content in the hydrocarbon source. Thus, pyrolysis of acetylene and $\mathrm{Fe}(\mathrm{CO})_{5}$ yields SWNTs at the outlet of the furnace. MWNTs are obtained in the inlet of the furnace by the same procedure. Use of benzene yields nanorods at the inlet and metal encapsulated graphite nanoparticles at the outlet end of the furnace. Since the SWNTs ob- tained are around $1 \mathrm{~nm}$ diameter, the metal particles produced from the pyrolysis of the organometallic precursors must be of this diameter atmost.

Most of the SWNTs as synthesized are closed at one end. They can be opened by stirring in $\mathrm{HCl}$ [16]. They are cleaned by refluxing in nitric acid (Fig. 7a). Acidwashed SWNTs can be decorated by metal nanoparticles (Fig. 7b). In Fig. 7(c) we show the HREM image of a SWNT opened at one end by stirring in $\mathrm{HCl}$ for $5 \mathrm{~h}$ at room temperature. It is known that MWNTs get opened by boiling in $\mathrm{HNO}_{3}[17,18]$. The opened SWNTs can be filled by metals. For example, they were stirred in a saturated solution of $\mathrm{PdCl}_{2}$ for $48 \mathrm{~h}$, washed with distilled $\mathrm{H}_{2} \mathrm{O}$ several times and then centrifuged. The black residue was dried in oven at $333 \mathrm{~K}$ overnight and then reduced in $\mathrm{H}_{2}$ at $573 \mathrm{~K}$ for $1 \mathrm{~h}$. Figure $7(\mathrm{~d})$ shows a HREM image of a SWNT filled with Pd.

Since the method followed by us to prepare nanotubes by the pyrolysis of organometallic precursor-hydrocarbon mixture permits us to vary the partial pressure of the organometallic precursor and the hydrocarbon, we carried out several pyrolysis experiments with high concentrations of the metallocene in order to see whether aligned nanotubes could be obtained by this means.

In Fig. 8(a), (b) and (c), we show the SEM images of the nanotubes obtained by carrying out the pyrolysis of ferrocene at $1373 \mathrm{~K}$ in the apparatus shown in Fig. 1(b),

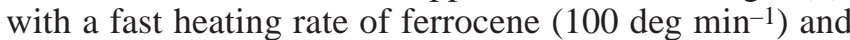
a high flow rate of $\operatorname{Ar}(1000 \mathrm{sccm})$. The images in Fig. 8(a) and (b) which are recorded in two different directions with respect to the axis of the nanotubes clearly reveal the extraordinary alignment. The image in Fig. 8(c) shows bundles of aligned nanotubes. TEM images of these nanotubes reveal that they are multi-walled, some of them partially filled with iron metal. Pyrolysis of ferrocene at $1170 \mathrm{~K}$ at a slow heating rate of $1 \mathrm{deg}$ $\mathrm{min}^{-1}$ under vacuum $\left(10^{-5}\right.$ Torr $)$ also yielded good quantities of aligned-nanotube bundles. In Fig. 8(d) we show the top view of such nanotubes. When the rate of heating

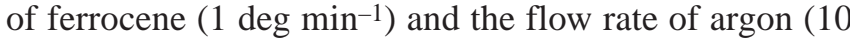
sccm) were low, fewer aligned nanotubes were obtained at a pyrolysis temperature of $1373 \mathrm{~K}$.

We have carried out the pyrolysis of ferrocene along with acetylene, by passing a mixture of argon and acetylene through the quartz tube. In Fig. 9(a), we show a SEM image of the aligned nanotubes obtained by the pyrolysis of a mixture of ferrocene and acetylene $(5 \mathrm{sccm})$ at $1373 \mathrm{~K}$ carried out with the apparatus in Fig. 1(b), in flowing Ar (1000 sccm). The alignment could be further improved by increasing the flow rate of $\mathrm{C}_{2} \mathrm{H}_{2}$. The SEM images in Fig. 9(b) and (c) obtained in this manner, show densely packed aligned nanotubes. The flow rate of acetylene in (b) was $50 \mathrm{sccm}$ and in (c) was $85 \mathrm{sccm}$. The TEM image in Fig. 9(d) reveals how well aligned these nanotubes are. The nanotubes in the bundles were generally closed and were 5-10 microns in length. Aligned nanotube bundles were also obtained by the pyrolysis of a mixture of two metallocenes along with acetylene. Thus pyrolysis of a mixture of ferrocene and nickelocene at $1373 \mathrm{~K}$ along with acetylene (flow rate=50 sccm) un- 

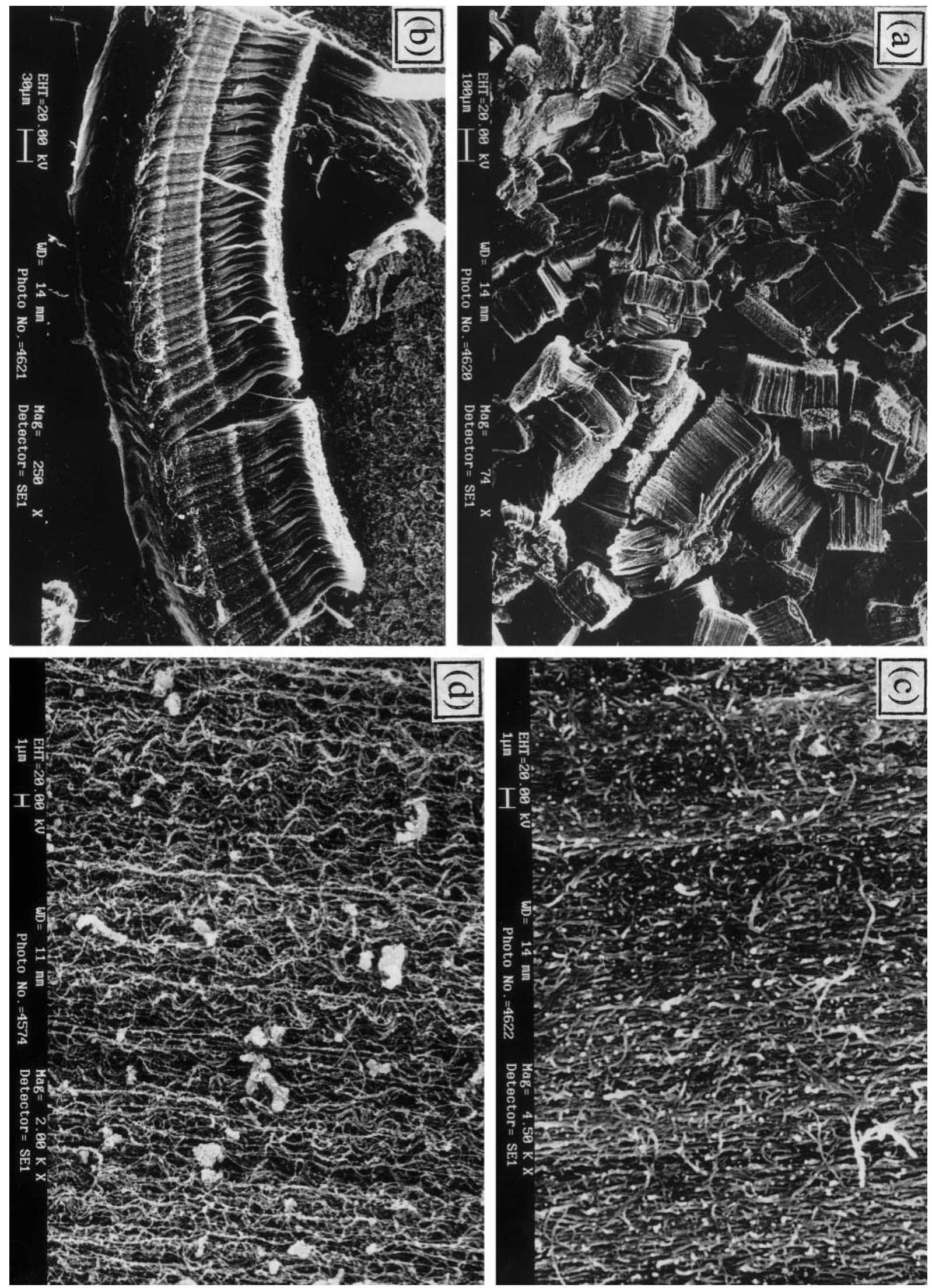

Fig. 10 (a), (b) and (c) show the SEM images of aligned-nanotube bundles obtained by the pyrolysis of a 1:1 mixture of ferrocene and nickelocene at $1373 \mathrm{~K}$ under a flow of $\mathrm{C}_{2} \mathrm{H}_{2}(50 \mathrm{sccm})$, $\mathrm{Ar}(975 \mathrm{sccm})$ and $\mathrm{H}_{2}(25 \mathrm{sccm})$. (d) shows aligned nanotubes obtained by the pyrolysis of a 1:1 mixture of ferrocene and cobaltocene at $1373 \mathrm{~K}$ in $\mathrm{C}_{2} \mathrm{H}_{2}(50 \mathrm{sccm}), \mathrm{Ar}(975 \mathrm{sccm})$ and $\mathrm{H}_{2}$ $(25 \mathrm{sccm})$ flow 

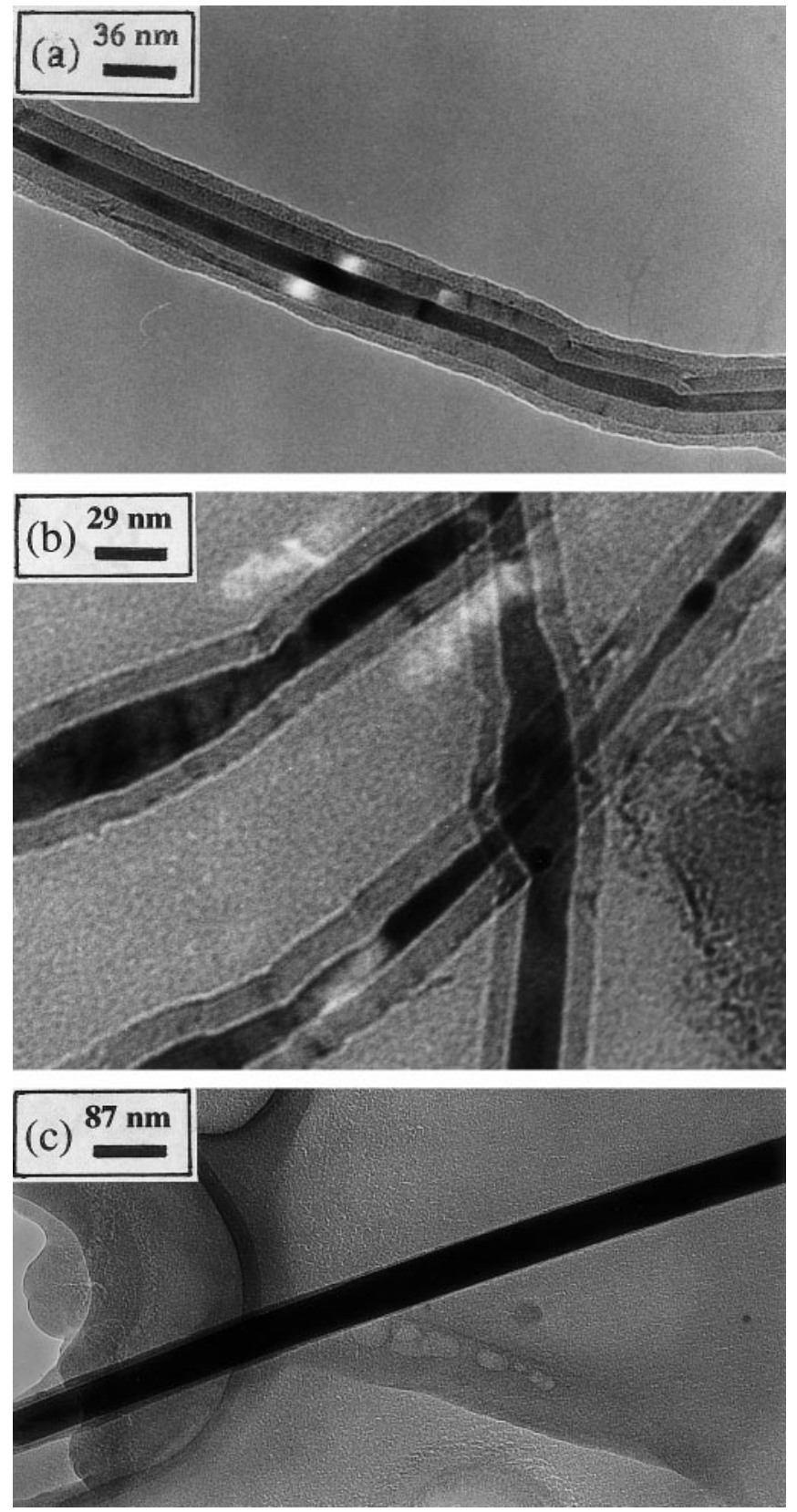

Fig. 11a-c TEM images of carbon coated iron nanorods obtained by the pyrolysis of ferrocene: (a),(b) at $1173 \mathrm{~K}$ under vacuum $\left(10^{-5}\right.$ Torr) and (c) at $1373 \mathrm{~K}$ in Ar flow of $10 \mathrm{sccm}$

der a flow of $\mathrm{Ar}$ and $\mathrm{H}_{2}$ (total flow rate=1000 sccm) yielded aligned nanotube bundles as shown by the SEM images in Fig. 10 (a), (b) and (c). Fig. 10 (d) shows a SEM image of aligned nanotubes obtained by the pyrolysis of ferrocene and cobaltocene at $1373 \mathrm{~K}$ in $\mathrm{C}_{2} \mathrm{H}_{2}$ $(50 \mathrm{sccm})$ and $\mathrm{Ar}+\mathrm{H}_{2}(1000 \mathrm{sccm})$ flow.

Pyrolysis of ferrocene was also carried out at a relatively fast heating rate of $50 \mathrm{deg} \mathrm{min}^{-1}$ by applying a vacuum $\left(10^{-5}\right.$ Torr $)$ at the exit end of the quartz tube. Here, the ferrocene sublimed under vacuum and the vapour got sucked into the pyrolysis zone. We mainly obtained carbon-coated iron nanorods (yield $\geq 60 \%$ ) in these experiments. In Fig. 11(a) and (b), we show the TEM images of iron nanorods with thick carbon coating, obtained by the pyrolysis of ferrocene at $1173 \mathrm{~K}$ under vacuum. We also obtained a fair proportion of nanorods when flow rate of Ar was low (10 sccm). In Fig. 11(c) we show the TEM image of a nanorod obtained by the pyrolysis of ferrocene at $1373 \mathrm{~K}$ at a Ar flow of $10 \mathrm{sccm}$. Such nanorods have been reported in the literature, by the reaction of carbon nanotubes with volatile oxide or halide species [19]. The present method of producing nanorods is however much simpler. The formation of iron metal in the form of particles or rods in the pyrolysis of ferrocene suggests that the mechanism of alignment of the nanotubes may be related to the magnetic nature of the nanorods or particles of iron.

\section{Conclusions}

In conclusion, the present study shows that the pyrolysis of hydrocarbon-organometallic mixtures provides an excellent route to produce different types of nanotubes. Benzene-metallocene mixtures yield MWNTs whereas the dilute acetylene-metallocene mixtures yield SWNTs. This may be because the carbon content in the former precursor is high. The use of hydrogen in the flow gas along with Ar minimizes the amorphous carbon coating on the nanotubes. Binary metallocene mixtures also yield isolated SWNTs. $\mathrm{Fe}(\mathrm{CO})_{5}$ is a good organometallic precursor to produce SWNTs by acetylene pyrolysis. The diameters of the SWNTs obtained in the present study are all around $1 \mathrm{~nm}$. Thus, the study confirms that on pyrolysis, the organometallic precursor molecules produce very small metal particles of $\sim 1 \mathrm{~nm}$ diameter, necessary for the formation of SWNTs. In the case of MWNTs the metal particles would be somewhat bigger $(1-10 \mathrm{~nm}$ diameter). Pyrolysis of ferrocene or ferrocene-acetylene mixture yields copious quantities of aligned nanotube bundles and such a ready method for the synthesis of nanotube bundles is of considerable importance. The alignment depends on the flow rate of the gases, heating rate of ferrocene and the diameter of the quartz pyrolysis tube. Nanorods have been obtained by carrying out the pyrolysis of ferrocene under vacuum or at low flow rate of argon gas.

Acknowledgement The authors thank the Indo-French Centre for Promotion of Advanced Research, New Delhi, for support.

\section{References}

1. Iijima S (1991) Nature 354:56; Rao CNR, Seshadri R, Govindaraj A, Sen R (1995) Mater Sci and Engg R15:209

2. Jose-Yacaman M, Miki-Yoshida M, Rendon L, Santiesteban JG (1993) Appl Phys Lett 62:202

3. Ivanov V, Nagy JB, Lambin Ph, Lucas A, Zhang XB, Zhang XF, Bernaerts D, Van Tendeloo G, Amelinckx S, Van Landuyt J (1994) Chem Phys Lett 223:329

4. Hernadi K, Fonseca A, Nagy JB, Bernaerts D, Riga J, Lucas A (1996) Synthetic Metals 77:31 
5. Rodriguez NM (1993) J Mater Res 8:3233

6. Dai H, Rinzler AG, Nikolaev P, Thess A, Colbert DT, Smalley RE (1996) Chem Phys Lett 260:471

7. Sen R, Govindaraj A, Rao CNR (1997) Chem Mater 9:2078

8. Iijima S, Ichihashi T (1993) Nature 363:603; Bethune DS, Kiang CH, de Vries MS, Gorman G, Savoy R, Vazquez J, Beyers R (1993) Nature 363:605

9. Thess A, Lee R, Nikolaev P, Dai H, Petit P, Robert J, Xu C, Lee YH, Kim SG, Rinzler AG, Colbert DT, Scuseria GE, Tomanek D, Fischer JE, Smalley RE (1996) Science 273:483

10. Guo T, Nikolaev P, Thess A, Smalley RE (1995) Chem Phys Lett 243:49

11. de Heer WA, Basca WS, Chatelain A, Gerfin T, HumphreyBaker R, Forro L, Ugarte D (1995) Science 268:845

12. Li WZ, Xie SS, Qian LX, Chang BH, Zou BS, Zhou WY, Zhao RA, Wang G (1996) Science 274:1701
13. Terrones M, Grobert N, Olivares J, Zhang JP, Terrones H, Kordatos K, Hsu WK, Hare JP, Townsend PD, Prassides K, Cheetham AK, Kroto HW, Walton DRM (1997) Nature 388:52

14. Journet C, Maser WK, Bernier P, Loiseau A, Lamy de la Chapelle M, Lefrant S, Deniard P, Lee R, Fischer JE (1997) Nature 388:756

15. Seraphin S, Zhou D (1994) Appl Phys Lett 64:2087

16. Sloan J, Hammer J, Zwiefka-Sibley M, Green MLH (1998) Chem Commun 347

17. Tsang SC, Chen YK, Harris PJF, Green MLH (1994) Nature 372:159

18. Satishkumar BC, Govindaraj A, Subbanna GN, Mofokeng J, Rao CNR (1996) J Phys B 29:4925

19. Dai H, Wong EW, Lu YZ, Fan S, Lieber CM (1995) Nature 375:769 